\title{
THE PREVELANCE OF METABOLIC SYNDROME ON THE SAMPLE OF PARAMEDICS
}

\section{DOROTA RĘBAK ${ }^{1}$, EDYTA SULIGA², URSZULA GRABOWSKA ${ }^{1}$, and STANISŁAW GLUSZEK ${ }^{1,3}$}

${ }^{1}$ The Jan Kochanowski University (UJK) in Kielce, Kielce, Poland

The Faculty of Medicine and Health Sciences, The Institute of Medical Sciences

${ }^{2}$ The Jan Kochanowski University (UJK) in Kielce, Kielce, Poland

The Faculty of Medicine and Health Sciences, The Institute of Nursing and Obstetrics

${ }^{3}$ Provincial Polyclinic Hospital in Kielce, Kielce, Poland

Clinical Department of General Oncology and Endocrinology Surgery

\begin{abstract}
Objectives: The term metabolic syndrome (MetS) refers to the coexistence of interlinked risk factors of metabolic origin, contributing to the development of arteriosclerotic cardiovascular diseases as well as type 2 diabetes and their cardiovascular complications. The aim of the study is the assessment of the prevalence of MetS among paramedics of the Świętokrzyskie Center of Emergency Medical Services, depending on the adopted diagnostic criteria. Material and Methods: The study included 140 paramedics ( 2 women and $138 \mathrm{men}$ ), aged 23-60 years old (median $=43$ years, average age $=41.5$ years, standard deviation $=10.8$ years). The age distribution of the subjects was significantly different from the normal distribution ( $\mathrm{p}$-value $<0.0001)$. The oldest age group (50 years old and above) was overrepresented by nearly a half compared to the youngest group (up to 29 years old). Metabolic syndrome was defined on the basis of the International Diabetes Federation (IDF) criteria from 2005 and IDF in agreement with the American Heart Association/National Heart, Lung and Blood Institute (AHA/NHLBI) from 2009. Results: According to the IDF/2005 criteria, in which the necessary condition is the diagnosis of central obesity, MetS was recorded in $26.4 \%$ of the subjects ( 37 people). This is statistically significantly less often than the IDF/AHA/NHLBI/2009 definition of $p=0.001-35 \%$. The frequency of the MetS occurrence was statistically significantly related to the age of the subjects and the age groups. Conclusions: The prevalence of the MetS in the subject group is evaluated to be significant. The prevalence of MetS is diversified by the applied diagnostic criteria with age being the factor increasing its frequency. The most common factor influencing the prevalence of MetS is blood pressure and waist circumference. Int J Occup Med Environ Health 2018;31(6):741-751
\end{abstract}

Key words:

Metabolic syndrome, Paramedics, Prevalence, Criterion, IDF/2005, IDF/2009

\section{INTRODUCTION}

The term „metabolic syndrome” (MetS) was used for the first time in 1981 and was defined by the researchers Hanefeld and Leonhart [1]. The components of the syndrome include: obesity, hyperlipidemia, diabetes, gout and hypertension, while its development is favored by: excessive food consumption, lack of physical activity and genetic predisposition [1]. However, the above cited researchers were not the first ones who made an attempt at systematizing the notion of metabolic syndrome. The first report is associated with the name of Dutch scientist Nicolaas Tulp and his work published in 1641, entitled

Funding: this study was supported by Ministry of Science and Higher Education (project No. 615501 entitled "Professional suitability of paramedics through the psychophysical aspects like obesity and coherence," project manager: Prof. Stanisław Głuszek).

Received: May 9, 2017. Accepted: January 26, 2018.

Corresponding author: Dorota Rębak, Jan Kochanowski University in Kielce, The Faculty of Medicine and Health Sciences, The Institute of Medical Sciences, al. IX Wieków Kielc 19, 25-317 Kielce, Poland (e-mail: dorotar@ujk.edu.pl). 
Observationum medicarum libri tres [2]. The studies on MetS are still the subject of several scientific publications. The interests of contemporary researchers involve the etiology and pathogenesis of MetS, resulting from the possibilities provided by technological development, related particularly to molecular, genetic and new studies. The growing epidemiological problem of MetS made it necessary to adjust the diagnostic criteria and devise it so that everyday clinical practice would not limit the possibility of application and in a simple way allow us to diagnose MetS.

Metabolic syndrome has been defined by the World Health Organization (WHO) [3], the European Group for the Study of Insulin Resistance (EGIR) [4], the National Cholesterol Education Program (NCEP), the Adult Treatment Panel (ATP III) [5,6], the American Association of Clinical Endocrinologist (AACE) [7]. The adopted criteria were criticized and they were applied in various degrees. Researchers involved in the assessment of MetS prevalence, applying different criteria obtained a different degree of its prevalence [8,9]. Therefore, there was the need to devise a uniform diagnostic criteria for MetS.
In 2005, the International Diabetes Federation (IDF) announced diagnostic criteria for defining MetS, being a modification of the NCEP-ATP III criteria. The essential condition of MetS diagnosis involves central obesity. The definition of MetS does not take into account the drug resistance to insulin given that the latter is highly connected to the central obesity and as such there is no need to focus on it. In line with IDF/2005, the occurrence of MetS is confirmed by: central obesity ( $\geq 94 \mathrm{~cm}$ (males - M), $80 \mathrm{~cm}($ females - F)) and at least 2 out of 4 following factors: triglycerides concentration $\geq 150 \mathrm{mg} / \mathrm{dl}$, high-density lipoprotein (HDL) cholesterol concentration - men: $<40 \mathrm{mg} / \mathrm{dl}$; women: $<50 \mathrm{mg} / \mathrm{dl}$, blood pressure: systolic $\geq 130 \mathrm{~mm} \mathrm{Hg}$ or diastolic $\geq 85 \mathrm{~mm} \mathrm{Hg}$, fasting glucose concentration $\geq 100 \mathrm{mg} / \mathrm{dl}$ ( $\geq 5,6 \mathrm{mmol} / \mathrm{l}$ ) [10] (Table 1). An obvious advantage of this definition is its simplicity, facilitating diagnostics and identification of individuals with MetS. However, the assumption that MetS may only occur in people with central obesity seems controversial. This criticism resulted in further adjustments - NCEP-ATP III [11].

Table 1. Definition of metabolic syndrome according to International Diabetes Federation (IDF) [10]

\begin{tabular}{|c|c|}
\hline Factor & Reference values \\
\hline \multicolumn{2}{|l|}{ Essential condition } \\
\hline central obesity & $\begin{array}{l}\text { waist circumference - men: }>94 \mathrm{~cm} \text {; women: }>80 \mathrm{~cm} \text { in the European population; and specific } \\
\text { values for other ethnic groups. If body mass index }(\mathrm{BMI}) \text { equals }>30 \mathrm{~kg} / \mathrm{m}^{2} \text {, the measurement } \\
\text { of waist circumference is not necessary to determine central obesity }\end{array}$ \\
\hline \multicolumn{2}{|l|}{ Additional criterion ${ }^{\mathrm{a}}$} \\
\hline triglycerides & $\geq 150 \mathrm{mg} / \mathrm{dl}(\geq 1.7 \mathrm{mmol} / \mathrm{l})$ or hypertriglyceridemia treatment \\
\hline $\begin{array}{l}\text { high density liprotein (HDL) } \\
\text { cholesterol }\end{array}$ & $\begin{array}{l}\text { men: }<40 \mathrm{mg} / \mathrm{dl}(<1.03 \mathrm{mmol} / \mathrm{l}) \text {; women: }<50 \mathrm{mg} / \mathrm{dl}(<1.29 \mathrm{mmol} / \mathrm{l}) \text { or the treatment } \\
\text { of low HDL cholesterol concentration }\end{array}$ \\
\hline blood pressure & systolic $\geq 130 \mathrm{~mm} \mathrm{Hg}$ or diastolic $\geq 85 \mathrm{~mm} \mathrm{Hg}$, or the treatment of pre-diagnosed hypertension \\
\hline fasting glucose & $\begin{array}{l}\geq 100 \mathrm{mg} / \mathrm{dl} \text { ( } \geq 5.6 \mathrm{mmol} / \mathrm{l}) \text {; or pre-diagnosed diabetes. If fasting glucose concentration has } \\
\text { a higher value than the one stated above, it is necessary to conduct the oral glucose tolerance } \\
\text { test (OGTT), which is not essential to diagnose metabolic syndrome }\end{array}$ \\
\hline
\end{tabular}

a At least 2 out of 4 factors.

Based on: Zimmet et al. [10]. 
Table 2. Modified International Diabetes Federation (IDF) criteria in agreement with American Heart Association/ National Heart, Lung and Blood Institute (AHA/NHLBI) from 2009 [12]

\begin{tabular}{ll}
\hline \multicolumn{1}{c}{ Essential condition $^{\mathrm{a}}$} & \multicolumn{1}{c}{ Reference values } \\
\hline $\begin{array}{l}\text { Waist circumference (dependent } \\
\text { on the population group) }\end{array}$ & Caucasian $\geq 94 \mathrm{~cm}($ males $(\mathrm{M})), \geq 80 \mathrm{~cm}(\mathrm{females}(\mathrm{F}))$ \\
& American (USA, Canada $\geq 102 \mathrm{~cm}(\mathrm{M}), \geq 88 \mathrm{~cm}(\mathrm{~F})$ \\
& Middle East and Mediterranean countries $\geq 94 \mathrm{~cm}(\mathrm{M}), \geq 80 \mathrm{~cm}(\mathrm{~F})$ \\
& Asian $\geq 90 \mathrm{~cm}(\mathrm{M}), \geq 80 \mathrm{~cm}(\mathrm{~F})$ \\
Triglycerides & $\geq 150 \mathrm{mg} / \mathrm{dl}$ or administered hypolipemizing treatment \\
High density liprotein (HDL) cholesterol & $<40 \mathrm{mg} / \mathrm{dl}(\mathrm{M}),<50 \mathrm{mg} / \mathrm{dl}(\mathrm{F})$ or administered treatment \\
Blood pressure & $\geq 130 / 85 \mathrm{~mm} \mathrm{Hg}$ or administered antihypertensive treatment \\
Glycemia & $\geq 100 \mathrm{mg} / \mathrm{dl}$ or applied hypoglycemic treatment \\
\hline
\end{tabular}

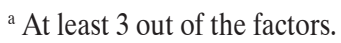

Based on: Alberti et al. [12].

The consensus in this issue involves the criteria from 2009, announced by the IDF in agreement with the American Heart Association/National Heart, the Lung and Blood Institute (AHA/NHLBI). According to their recommendations, for the evaluation of MetS, 3 out of 5 factors need to be confirmed: central obesity ( $\geq 94 \mathrm{~cm}(\mathrm{M}), 80 \mathrm{~cm}(\mathrm{~F})$ ), triglycerides concentration $\geq 150 \mathrm{mg} / \mathrm{dl}$, HDL cholesterol concentration $<40 \mathrm{mg} / \mathrm{dl}(\mathrm{M}),<50 \mathrm{mg} / \mathrm{dl}(\mathrm{F})$, values of blood pressure $\geq 130 / 85 \mathrm{~mm} \mathrm{Hg}$ and glycemia $\geq 100 \mathrm{mg} / \mathrm{dl}$ [12] (Table 2).

The term metabolic syndrome refers to the coexistence of interlinked risk factors of metabolic origin, contributing to the development of arteriosclerotic cardiovascular diseases as well as type 2 diabetes and their cardiovascular complications. Dominating etiological MetS factors include closely interrelated abdominal obesity and drug resistance to insulin $[11,13]$.

The most recognized elements of MetS are among others: higher blood pressure [6]. Inclusion of the higher blood pressure into the diagnostic criteria of MetS results most likely for the fact that among around $50 \%$ of the patients with blood pressure, the drug resistance to insulin is also recognized. Those patients are at the same time in the risk group of the cardiovascular diseases [14].
The aim of the study is the assessment of the prevalence of MetS among paramedics of the Świettokrzyskie Center of Emergency Medical Services depending on the adopted diagnostic criteria.

\section{MATERIAL AND METHODS}

The studies were carried out in the Research Studies Laboratory of the Institute of Medical Sciences, the Faculty of Medicine and Health Sciences of the Jan Kochanowski University in Kielce, in the framework of the conducted research project financed with the statutory research funds, the title of which is Professional Suitability of Paramedics through the Psychophysical Aspects like Obesity and Coherence. The studies were approved by the Bioethical Commission, permit No. 14/2014 and the management board of Świętokrzyskie Center of Emergency Medical Services (ŚCRMiTS) in Kielce. The studies were carried out between October-December 2015.

The subject group comprised of emergency medical professionals of the Świętokrzyskie Center of Emergency Medical Services in Kielce (ŚCRMiTS) excluding doctors. The group selection was based on target screening. The inclusion criteria of the studied group included: 
- possessing qualifications which entitle a person to work in emergency medical teams with the exclusion of doctors (the aim was to focus on paramedics themselves, not the emergency teams which include doctors and/or nurses),

- active performance of the job paramedics,

- performing emergency medical activities in out-of-clinic conditions and Emergency Communication Center.

The study included 140 paramedics ( 2 female and 138 male), aged 23-60 years old $($ median $(\mathrm{Me})=43$ years, mean $(\mathrm{M})=41.5$ years, standard deviation $(\mathrm{SD})=10.8$ years) . The age distribution of the subjects was significantly different from the normal distribution ( $\mathrm{p}$-value $<0.0001$ ). The oldest age group (50 years and above) was overrepresented by nearly a half more compared to the youngest group (up to 29 years). A degree in the profession of emergency medical services was declared by 133 people ( $95 \%$ of all participants), and 7 people (5\%) had a nursing background.

The studies were conducted by a qualified nurse in a treatment room of certain Ambulance Stations and Substations of ŚCRMiTS. The procedure involved a questionnaire interview, blood pressure measurements, taking fasting venous blood samples as well as anthropometric measurements.

\section{Assessment of health}

Blood pressure measurements were performed according to the recommendations included in the 2013 European Society for Hypertension/European Society for Cardiology $(\mathrm{ESH} / \mathrm{ESC})$ Guidelines concerning the procedure in the case of blood hypertension - the Working Group of the European Society for Hypertension (ESH) and European Society for Cardiology (ESC) for hypertension management [15] by means of a semi-automatic (one model) auscultatory sphygmomanometer, at rest, when seated, on the right upper arm.

Biochemical tests included fasting lipidogram and fasting glycemia. Fasting venous samples were collected while the subject was seated, by means of a vacuum system, the transport $(\max 2 \mathrm{~h}$ ) temperature was the same as the temperature of the diagnostic laboratory of the Provincial Polyclinic Hospital in Kielce. The blood samples were coded, the questionnaire interview was designated with the same number. Blood tests were performed by means of the biochemical AU 680 Beckman Coulter analyzer. Beckman Coulter reagents were used in order to mark total and HDL cholesterol, triglycerides and glucose. Lowdensity lipoprotein (LDL) cholesterol concentration was calculated by means of the Friedewald formula.

Waist circumference was measured with an approved BASELINE anthropometric tape. The measurement was performed when the subject was in an upright positon, the measurement taken between the costal margin and iliac wings.

Metabolic syndrome (MetS) was defined on the basis of the IDF criteria (International Diabetes Federation) from 2005 and IDF in agreement with AHA (American Heart Association)/NHLBI (National Heart, Lung and Blood Institute) from 2009 (Tables 1 and 2).

\section{Statistical analysis}

For data compilation, a Microsoft Excel 2010 worksheet was used. The statistical analysis was performed by means of MS Excel, Statistica (StatSoft, Inc. (2014) programs: Statistica (data analysis software system), version 12 and $\mathrm{R}$ version 3.1.2.

In order to present quantitative data, the minimum, maximum, average, median and standard deviation were applied. The distributions of qualitative data were described by means of absolute values and percentages. The normality of the distributions was evaluated with the use of the Shapiro-Wilk test. In the case of qualitative data: for the assessment of the significance of differences between the groups, the analysis of variance or the Kruskal-Wallis test was applied (when ANOVA assumptions were not met). After rejecting the hypothesis on the ba- 
sis of a lack of differences between the groups, multiple comparisons tests were used (the post-hoc Tukey test or the signed-rank test). The correlation between qualitative data was analyzed by means of the Pearson linear correlation coefficient or Spearman's rank correlation coefficient. The association between the qualitative data was determined by means of the $\mathrm{Chi}^{2}$ test or the Fisher's exact test. All applied statistical tests were two-tailed. A statistical significance was confirmed when the p-value was lower than 0.05 .

Examination findings presented in the study are part of a more comprehensive project relating to the professional suitability of paramedics.

\section{RESULTS}

\section{Prevalence of the MetS factors}

Metabolic syndrome was not found in 2 female study participants. The prevalence of the MetS components in the subject group were compiled (IDF/2005 and IDF/NHLBI/ AHA/2009) (Table 3). Hypertension was the most frequently diagnosed abnormal score (or administered antihypertensive treatment), which was diagnosed in $75 \%$ of the subjects. It statistically significantly varied in the subject age groups $(p=0.03)$. The least frequent was a low HDL concentration, which concerned $20.7 \%$ of the subjects. Glucose concentration increased statistically significantly with age. Abnormal values were found in $24.3 \%$ of all subjects. Abnormal triglycerides concentrations were present in the oldest group (40-49 years) $-54.1 \%$, and the greatest percentage of people $(60.5 \%)$ with excess waist circumference was found in the 50-60-year-olds.

For each subject a number of factors listed in the IDF criteria from 2005 and 2009 was determined. Percentage factors were analyzed: central obesity, triglycerides, HDL cholesterol and glucose concentration, and blood pressure. Only in 5\% of all subjects, none of these factors was found, but also in $5 \%$ a coexistence of 5 possible factors occurred (group 40-49 years and 50-60 years). In all subjects, 2 MetS factors were found most often $-33.6 \%$. The group up to 29 years old was characterized by the most frequent occurrence of 1 factor, in the group of 30-39 years old and 40-49 years old - 2 factors, while the 50-60-year-olds were characterized by 3 factors (Table 4).

Table 3. The prevalence of metabolic syndrome (MetS) components in the subject age group compiled from IDF/2005 [10] and IDF/NHLBI/AHA from 2009 [12]

\begin{tabular}{lcccccccccc}
\hline \multicolumn{10}{c}{ MetS components $^{2}$} \\
\hline Age group & $\begin{array}{c}\text { hypertension }^{\mathrm{a}} \\
(\mathrm{N}=105(75 \%))\end{array}$ & $\begin{array}{c}\text { triglycerides }^{\mathrm{b}} \\
(\mathrm{N}=64(45.7 \%))\end{array}$ & $\begin{array}{c}\text { waist circumference }^{\mathrm{c}} \\
(\mathrm{N}=72(51.4 \%))\end{array}$ & $\begin{array}{c}\text { glycemia }^{\mathrm{d}} \\
(\mathrm{N}=34(24.3 \%))\end{array}$ & $\begin{array}{c}\text { HDL }^{\mathrm{e}} \\
(\mathrm{N}=29(20.7 \%))\end{array}$ \\
\cline { 2 - 11 } & $\mathrm{n}(\%)$ & $\mathrm{p}$ & $\mathrm{n}(\%)$ & $\mathrm{p}$ & $\mathrm{n}(\%)$ & $\mathrm{p}$ & $\mathrm{n}(\%)$ & $\mathrm{p}$ & $\mathrm{n}(\%)$ & $\mathrm{p}$ \\
\hline 329 years & $20(69.0)$ & 0.03 & $11(37.9)$ & 0.31 & $11(37.9)$ & 0.32 & $2(6.9)$ & $<0.0001$ & $4(13.8)$ & 0.66 \\
30-39 years & $19(61.3)$ & 0.03 & $11(35.5)$ & 0.31 & $16(51.6)$ & 0.32 & $1(3.2)$ & $<0.0001$ & $8(25.8)$ & 0.66 \\
40-49 years & $30(81.1)$ & 0.03 & $20(54.1)$ & 0.31 & $19(51.4)$ & 0.32 & $8(21.6)$ & $<0.0001$ & $7(18.9)$ & 0.66 \\
50-60 years & $36(83.7)$ & 0.03 & $22(51.2)$ & 0.31 & $26(60.5)$ & 0.32 & $23(53.5)$ & $<0.0001$ & $10(23.3)$ & 0.66 \\
\hline
\end{tabular}

a Blood pressure $\geq 130 / 85 \mathrm{~mm} \mathrm{Hg}$ or administered antihypertensive treatment.

${ }^{\mathrm{b}}$ Triglycerides concentration $\geq 150 \mathrm{mg} / \mathrm{dl}$ or administered hypolipemizing treatment.

c $\geq 94 \mathrm{~cm}($ males $(\mathrm{M}))$, $\geq 80 \mathrm{~cm}($ females $(\mathrm{F}))$.

${ }^{\mathrm{d}}$ Glycemia $\geq 100 \mathrm{mg} / \mathrm{dl}$ or applied hypoglycemic treatment.

${ }^{\mathrm{e}}$ High density liprotein (HDL) cholesterol concentration $<40 \mathrm{mg} / \mathrm{dl}(\mathrm{M}),<50 \mathrm{mg} / \mathrm{dl}(\mathrm{F})$ or administered treatment. 
Table 4. Metabolic syndrome (MetS) components according to International Diabetes Federation/American Heart Association/ National Heart, Lung and Blood Institute - IDF/ AHA/NHLBI/2009 in the subject group [12]

\begin{tabular}{|c|c|c|c|c|c|c|}
\hline \multirow{2}{*}{ Age group } & \multicolumn{6}{|c|}{$\begin{array}{l}\text { Components of metabolic syndrome } \\
{[\mathrm{n}(\%)]}\end{array}$} \\
\hline & 0 & 1 & 2 & 3 & 4 & 5 \\
\hline$\leq 29$ years $(\mathrm{N}=29)$ & $0(0.0)$ & $14(48.3)$ & $12(41.4)$ & $2(6.9)$ & $1(3.5)$ & $0(0.0)$ \\
\hline $30-39$ years $(\mathrm{N}=31)$ & $2(6.5)$ & $10(32.3)$ & $14(45.2)$ & $3(9.7)$ & $2(6.5)$ & $0(0.0)$ \\
\hline $40-49$ years $(\mathrm{N}=37)$ & $3(8.1)$ & $6(16.2)$ & $13(35.1)$ & $10(27.0)$ & $3(8.1)$ & $2(5.4)$ \\
\hline $50-60$ years $(\mathrm{N}=43)$ & $2(4.7)$ & $7(16.3)$ & 8 (18.6) & $15(34.9)$ & $6(14.0)$ & $5(11.6)$ \\
\hline Total $(\mathrm{N}=140)$ & $7(5.0)$ & $37(26.4)$ & $47(33.6)$ & $30(21.4)$ & $12(8.6)$ & $7(5.0)$ \\
\hline
\end{tabular}

\section{Prevalence of MetS related to applied critieria} IDF/NHLBI/AHA/2009

At least 3 of the analyzed factors were confirmed in $35 \%$ of all subjects (49 individuals), therefore showing MetS occurrence, according to the IDF/NHLBI/AHA criteria from 2009.

In the group with MetS, the criterion related to blood pressure (systolic $\geq 130 \mathrm{~mm} \mathrm{Hg}$ or diastolic $\geq 85 \mathrm{~mm} \mathrm{Hg}$ or administered antihypertensive treatment) was met by $95.9 \%$ (47 subjects) of all individuals in this group, while the exceeded values of systolic and diastolic blood pressure were noted in 32 individuals (in the remaining 14 subjects too high values of blood pressure, systolic or diastolic was observed). The criterion related to triglycerides, waist cir- cumference, glycemia and HDL, was met respectively by $81.6 \%, 77.6 \%, 57.1 \%$ and $40.8 \%$ individuals in the group with MetS (Table 5). The frequency of MetS occurrence was statistically significantly ( $\mathrm{p}$-value $<0.001$ ) related to the age of the subjects and in the age groups up to 29 years old, 30-39 years old, 40-49 years old and 50-60 years old equaled respectively $10.3 \%, 16.1 \%, 40.5 \%$ and $60.5 \%$ (Figure 1).

\section{IDF/2005}

While evaluating the prevalence of MetS, according to the IDF/2005 criteria, for the occurrence of which central obesity constitutes an essential condition, MetS was recorded in $26.4 \%$ subjects (37 individuals), statistically

Table 5. Prevalence of metabolic syndrome (MetS) components among researched people with MetS according to Diabetes Federation/American Heart Association/National Heart, Lung and Blood Institute (IDF/AHA/NHLBI)/2009 [12] and IDF/2005 [10]

\begin{tabular}{|c|c|c|}
\hline \multirow{2}{*}{ Factor } & \multicolumn{2}{|c|}{$\begin{array}{l}\text { Subjects } \\
{[\mathrm{n}(\%)]}\end{array}$} \\
\hline & $\begin{array}{c}\text { IDF/AHA/NHLBI/2009 } \\
(\mathrm{N}=49)\end{array}$ & $\begin{array}{l}\mathrm{IDF} / 2005 \\
(\mathrm{~N}=37)\end{array}$ \\
\hline $\begin{array}{l}\text { Waist circumference/central } \\
\text { obesity }(\geq 94 \mathrm{~cm}(\text { males }(\mathrm{M})), \geq 80 \mathrm{~cm}(\text { females }(\mathrm{F}))\end{array}$ & $38(77.6)$ & $37(100.0)$ \\
\hline Triglycerides ( $\geq 150$ mg/dl) & $40(81.6)$ & $29(78.4)$ \\
\hline High density lipoprotein cholesterol (HDL) $(<40 \mathrm{mg} / \mathrm{dl}(\mathrm{M}))$ & $20(40.8)$ & $14(37.8)$ \\
\hline Blood pressure $(\geq 130 / 85 \mathrm{~mm} \mathrm{Hg})$ & $47(95.9)$ & $35(94.6)$ \\
\hline Glycemia ( $\geq 100 \mathrm{mg} / \mathrm{dl}$ ) & $28(57.1)$ & $20(54.1)$ \\
\hline
\end{tabular}


significantly less often than in the case of the IDF/AHA/ NHBLI/2009 definition, at $p=0.001$. In this group, blood pressure was also a factor present most often and concerned $94.6 \%$ of the subjects with MetS. Next, the following was noted: triglycerides $-78.4 \%$, glycemia $-54.1 \%$, the lowest percentage was obtained in the scope of HDL cholesterol $-37.8 \%$ (Table 5). The average age in the group with MetS was significantly higher in comparison with the group without MetS (48.9 years old vs. 38.8 years old, $\mathrm{p}<0.0001)$. The frequency of MetS occurrence was significantly correlated with age $(\mathrm{p}=0.0002)$ and in the age groups $\leq 29$ years old, 30-39 years old, 4049 years old, 50-60 years old equaled respectively $6.9 \%, 12.9 \%, 27 \%$ and $48.8 \%$ (Figure 1).

\section{DISCUSSION}

Main points of the study are prevalence of MetS factors and diagnostic differences resulting from application of different criteria.

The attempt to assess the degree of MetS prevalence and its components was made because of the current state of increase of prevalence and clinical significance of their occurrence and due to the fat that MetS constitutes a risk factor in cardiovascular diseases and type 2 diabetes. The presence of MetS increases the risk of cardiovascular diseases twofold, raising the risk of the development of type 2 diabetes 5 times, increases the chances of general mortality by $6-7 \%$ and due to cardiovascular reasons, by $12-17 \%$, with cardiovascular death occurring 3.5-5.5 times more often in patients with MetS as compared with the general population [16-19]. For each subject, a number of the MetS risk factors was determined, included in the discussed criteria. Only in $5 \%$ of subjects, none of these factors was found. The most frequently noted abnormal score was hypertension (or administered antihypertensive treatment), which was diagnosed in $75 \%$ of the subjects. The least frequent was HDL concentration, which concerned $20.7 \%$ of the subjects. Similarly, in NATPOL PLUS (Nadciśnienie

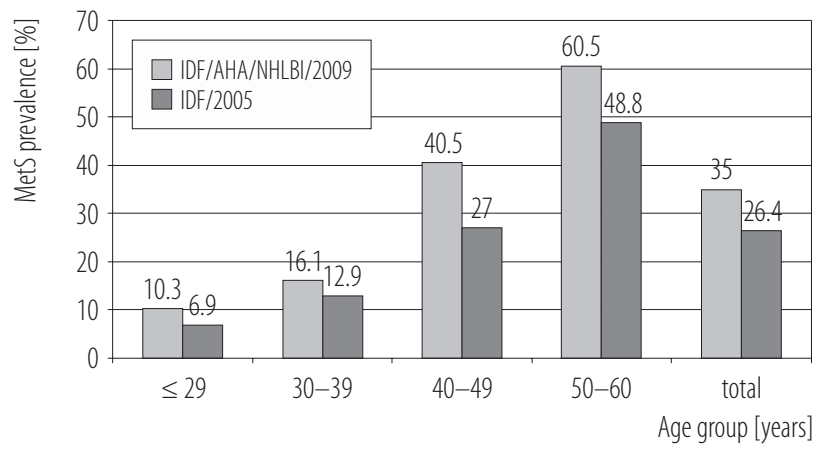

Fig. 1. Prevalence of metabolic syndrome (MetS) evaluated in accordance with International Diabetes Federation/ American Heart Association/National Heart, Lung and Blood Institute (IDF/AHA/NHLBI/2009) [12] and IDF/2005 [10] in general and in age groups

Tętnicze w Polsce Plus Zaburzenia Lipidowe i Cukrzy$\mathrm{ca}$ - the Arterial Hypertension in Poland Plus Lipid Disorders and Diabetes) (NCEP-ATP III) studies, an increased blood pressure was the most frequently revealed deviation from the adopted values and concerned $69 \%$ of men. Followed by an increase of triglycerides concentration - 34\% [20] in our own studies - 45.7\%. In PONS studies the most frequently observed abnormality was abdominal obesity and it concerned $75.1 \%$ of the subjects. Hypertension came second $-71 \%$. Lastly, similar to our own studies, was the low HDL concentration [21]. The studies conducted in the European countries of Italy and France confirm increased blood pressure to be the most common abnormality [22,23].

Metabolic syndrome evaluated according to the IDF/ AHA/NHLBI criteria from 2009 and IDF from 2005, was found respectively in $35 \%$ and $26.4 \%$ of all subject paramedics in the Świętokrzyskie Province (23-60-year-olds). Authors have not encountered any other study similar to theirs done on the sample of paramedics. The prevalence of MetS in general population in the Świętokrzyskie Province is revealed by the results of PONS studies (IDF/AHA/NHLBI/2009). According to these studies, MetS concerned $39.5 \%$ of the general population and 
49.9\% of men (45-64 years) [21]. The degree of prevalence of the MetS occurrence in Poland was assessed by (criteria NCEP-ATP III) the NATPOL PLUS studies - 20.3\% of the general population and $18 \%$ of men, Pol-MONICA (Multinational Monitoring of Trends and Determinants in Cardiovascular Disease - Polish arm) studies - 20\% men aged between 35-64 years old and WOBASZ (Wieloośrodkowe Ogólnopolskie Badanie Stanu Zdrowia Ludności - the Multi-center National Population Health Examination Survey) studies - for men: 26\% (AHA/ NHLBI/2005) or $30.7 \%$ (IDF/2005) or $19.5 \%$ (NCEPATP/2001) or 22.80\% (NCEP-ATP/2005) [20,24-26].

Among 40- and 50-year-old men from Wrockaw, MetS was confirmed at the level of 35.5\% (IDF/AHA/NHBLI/2009) and $31.4 \%$ (IDF/2005). In the division into age groups, the researchers noted the degree of MetS prevalence for 40 -year-olds at $40.5 \%$ and $27 \%$ and for 50 -yearolds at $42.1 \%$ and $36.6 \%$ [27]. In the subject study group, higher indicators were found. In the group of 40-49-year-olds, it was $40.5 \%$ and $27 \%$, and in the group of 50-60-year-olds, it was significantly higher $-60.5 \%$ and $48.8 \%$. A higher indicator of the MetS occurrence according to IDF/2005, than in our own studies, was obtained by a researcher in the male population of the employees in the KGHM „Polska Miedź SA” holding company (402 men, 30-60 years old) $-44.78 \%$ of all subjects [28]. Literature of the subject confirms a growing tendency of MetS along with age [20,21,26,28-31]. Such a correlation was also achieved in our own studies. The frequency of the MetS occurrence was statistically significantly correlated with the age of the subjects and in the age groups up to 29-year-olds, 30-39-year-olds, 40-49-year-olds and 50-60-year-olds and equaled respectively $10.3 \%, 16.1 \%, 40.5 \%$ and $60.5 \%$ according to IDF/AHA/NHBLI/2009 and 6.9\%, 12.9\%, 27\%, $48.8 \%$ according to IDF/2009. Among the inhabitants of the Świętokrzyskie Province (IDF/2009) aged between 45-49 years old, the MetS prevalence equaled 27\%, 50-54-year-olds almost - 35\%, 55-59-year-olds - slightly higher than 40\%, 60-64-year-olds - 47\% [21], so a lower frequency than in our own studies. Among men from Wrocław, MetS was evaluated at the level of $30.4 \%$ in 40-year-olds, and $42.1 \%$ in 50-year-olds [28]. The differences in the values between our own studies and the cited ones may result from the significant difference of the number of participants in the subject groups. A higher prevalence of MetS occurrence obtained in particular age groups among paramedics and a confirmed upward tendency may be worrying and may constitute the basis for providing medical care for this group. It should be emphasized that in the youngest group up to 29 years old, MetS, depending on the adopted criteria, was found at the level of $10.3 \%$ and $6.9 \%$. In further age brackets the frequency of MetS almost doubled, with the exception of the last group, where a smaller increase was observed. Extensive studies on MetS show several associations of the occurrence and prevalence of MetS. It was observed, among others, that in people with metabolic syndrome the risk of cardiovascular diseases and diabetes increased proportionally to the number of the MetS components [32]. In the group of emergency medical professionals with MetS (IDF/2009) the criterion of blood pressure was met by $95.9 \%$, triglycerides $81.6 \%$, waist circumference $-77.6 \%$, hyperglycemia $-57.1 \%$ and HDL - $40.8 \%$ individuals with MetS. Taking the above into consideration, activities aimed at the prevention of cardiovascular complications and the development of diabetes in the subject group of emergency workers with MetS should become a priority, and in the broader perspective, a decrease in the predicted prognosis of metabolic syndrome in the assessment of risk related to cardiovascular and diabetes mortality.

The results of the conducted analyses point to the difference between the achieved degree of the MetS prevalence in the subject group, depending on the applied diagnostic criteria. Metabolic syndrome was found statistically more often according the IDF/AHA/NHBLI/2009 crite- 
ria $-35 \%$ than IDF/2005 - 26.4\% in the general population. The difference was also visible in age groups. Differences in the level of MetS prevalence, depending on the adopted criteria, have been confirmed in several scientific publications and raise further doubts, among others, in the scope of treatment. There have not been any prospective clinical studies conducted, either, which would assess how MetS treatment affects prognosis. Researchers also indicate the need to diagnose MetS on the basis of prospective clinical observations based on medical evidence (evidence based medicine - EBM) and not on experts' opinions [33,34]. However, one of the important directions of studies on MetS involves the identification of people characterized by an increased risk of cardiovascular disease, who should be provided with relevant medical care [35]. The survey indicates that it will be a clinicist to choose diagnostic criteria followed by appropriate treatment and prevention.

\section{CONCLUSIONS}

The prevalence of the MetS in the subject group is evaluated to be significant. The prevalence of MetS is diversified by the applied diagnostic criteria with age being the factor increasing its frequency.

The most common factor influencing the prevalence of MetS is blood pressure and waist circumference.

\section{REFERENCES}

1. Hanefeld M, Leonhardt W. [Metabolic Syndrome]. Dt. Gesundh-Wesen. 1981;36:545-51. German.

2. Erkelens DW, de Bruin TW, Castro Cabezas M. Tulp syndrome. Lancet. 1993;342(8886-8887):1536-7, https://doi.org/ 10.1016/S0140-6736(05)80093-5.

3. Alberti KG, Zimmet PZ. Definition, diagnosis and classification of diabetes mellitus and its complications. Part 1: Diagnosis and classification of diabetes mellitus: Provisional report of WHO consultation. Diabet Med. 1998;15(7):539-53, https://doi.org/10.1002/(SICI)1096-9136(199807)15:7<539:: AID-DIA668 >3.0.CO;2-S.
4. Balkau B, Charles MA. Comment of the provisional report from the WHO consultation. European Group for the Study of Insulin Resistance (EGIR). Diabet Med. 1999;16(5): 442-3, https://doi.org/10.1046/j.1464-5491.1999.00059.x.

5. Expert Panel on Detection, Evaluation, and Treatment of High Blood Cholesterol in Adults. Executive summary of the third report of the National Cholesterol Education Program (NCEP) Expert Panel on Detection, Evaluation, and Treatment of High Blood Cholesterol in Adults (Adult Treatment Panel III). JAMA. 2001;285(19):2486-97, https:// doi.org/10.1001/jama.285.19.2486.

6. National Cholesterol Education Program (NCEP) Expert Panel on Detection, Evaluation, and Treatment of High Blood Cholesterol in Adults (Adult Treatment Panel III). Third report of the National Cholesterol Education Program (NCEP) Expert Panel on Detection, Evaluation, and Treatment of High Blood Cholesterol in Adults (Adult Treatment Panel III) final report. Circulation. 2002;106(25): 3143-421.

7. Einhorn D, Reaven GM, Cobin RH, Ford E, Ganda OP, Handelsman Y, et al. American College of Endocrinology position statement on the insulin resistance syndrome. Endocr Pract. 2003;9(3):237-52.

8. The Decode Study Group, Qiao Q. Comparison of three different definitions for the metabolic syndrome in non-diabetic Europeans. Br J Diabetes Vasc Dis. 2005;5(3):161-8, https://doi.org/10.1177/14746514050050030901.

9. Ford ES, Giles WH. A comparison of the prevalence of the metabolic syndrome using 2 proposed definitions. Diabetes Care. 2003;26(3):575-81, https://doi.org/10.2337/dia care.26.3.575.

10. Zimmet P, Magliano D, Matsuzawa Y, Alberti G, Shaw J. The metabolic syndrome: A global public health problem and a new definition. J Atheroscler Thromb. 2005;12(6):295-300.

11. Grundy SM, Cleeman JI, Daniels SR, Donato KA, Eckel RH, Franklin BA, et al. Diagnosis and management of the metabolic syndrome. An American Heart Association/National Heart, Lung, and Blood Institute Scientific Statement. 
Circulation. 2005;112:2735-52, https://doi.org/10.1161/CIRCULATIONAHA.105.169404.

12. Alberti KG, Eckel RH, Grundy SM, Zimmet PZ, Cleeman JI, Donato KA, et al. Harmonizing the metabolic syndrome. A joint interim statement of the International Diabetes Federation Task Force on Epidemiology and Prevention; National Heart, Lung, and Blood Institute; American Heart Association; World Heart Federation; International Atherosclerosis Society; and International Association for the Study of Obesity. Circulation. 2009;120: 1640-5, https://doi.org/10.1161/CIRCULATIONAHA.109. 192644.

13. Carr DB, Utzschneider KM, Hull RL, Kodama K, Retzlaff BM, Brunzell JD, et al. Intra-abdominal fat is a major determinant of the National Cholesterol Education Program Adult Treatment Panel III criteria for the metabolic syndrome. Diabetes. 2004;53(8):2087-94, https://doi.org/ 10.2337/diabetes.53.8.2087.

14. Reaven GM. The metabolic syndrome: Requiescat in pace. Clin Chem. 2005;51(6):931-8, https://doi.org/10.1373/clinch em.2005.048611.

15. Grupa Robocza Europejskiego Towarzystwa Nadciśnienia Tętniczego (ESH) i Europejskiego Towarzystwa Kardiologicznego (ESC) do spraw postępowania w nadciśnieniu tętniczym. [ESH/ESC guidelines for the management ofarterial hypertension in 2013]. Kardiol Pol. 2013;71 Suppl. III:27-118, https://doi.org/10.5603/KP.2013.0177. Polish.

16. Grundy SM. Does a diagnosis of metabolic syndrome have value in clinical practise? Am J Clin Nutr. 2006;83(6):124851, https://doi.org/10.1093/ajcn/83.6.1248.

17. Ford ES. Risk for all-cause mortality, cardiovascular disease, and diabetes associated with the metabolic syndrome. A summary of the evidence. Diabetes Care. 2005;28(7): 1769-78, https://doi.org/10.2337/diacare.28.7.1769.

18. Isomaa B, Almgren P, Tuomi T, Forsén B, Lahti K, Nissén M, et al. Cardiovascular morbidity and mortality associated with the metabolic syndrome. Diabetes Care. 2001;24(4):683-9, https://doi.org/10.2337/diacare.24.4.683.
19. Lakka HM, Laaksonen DE, Lakka TA, Niskanen LK, Kumpusalo E, Tuomilehto J, et al. The metabolic syndrome and total and cardiovascular disease mortality in middle-aged men. JAMA. 2002;288(21):2709-16, https://doi.org/10.1001/ jama.288.21.2709.

20. Wyrzykowski B, Zdrojewski T, Sygnowska E, Biela U, Drygas W, Tykarski A, et al. [Epidemiology of metabolic syndrome in Poland. Results of the WOBASZ program]. Kardiol Pol. 2005;63:6(Suppl. 4):1-4. Polish.

21. Janszky I, Vatten L, Romundstad P, Laugsand LE, Bjorngard JH, Mańczuk M, et al. Metabolic syndrome in Poland The PONS Study. Ann Agric Environ Med. 2011;18(2):270-2.

22. Balkau B, Vernay M, Mhamdi L, Novak M, Arondel D, Vol S, et al. The incidence and persistence of the NCEP (National Cholesterol Education Program) metabolic syndrome. The French D.E.S.I.R. study. Diabetes Metab. 2003;29(5):52632, https://doi.org/10.1016/S1262-3636(07)70067-8.

23. Tocci G, Ferrucci A, Bruno G, Mannarino E, Nati G, Trimarco B, et al. Prevalence of metabolic syndrome in the clinical practice of general medicine in Italy. Cardiovasc Diagn Ther. 2015;5(4):271-9, https://doi.org/10.3978/j.issn.2223-3652. 2015.07.03.

24. Zdrojewski T, Bandosz P, Szpakowski P, Konarski P, Malinowski A, Wołkiewicz E. [Prevalence of the main risk factors for CVD diseases in Poland. Results of researches NATPOL PLUS]. Kardiol Pol. 2004;61(Suppl. IV):IV1-IV26. Polish.

25. Broda G, Szcześniewska D, Rywik S. [Prevalence of metabolic syndrome among adult population of Warsaw]. Med Metabol. 2003;7:225-9. Polish.

26. Sygnowska E, Piwońska A, Waśkiewicz A, Broda G. Socioeconomic factors and the risk of metabolic syndrome in the adult Polish population: The WOBASZ study. Kardiol Pol. 2012;70(7):718-27.

27. Ilow R, Regulska-Ilow B, Różańska D. Prevalence of metabolic syndrome among 40- and 50-year-old inhabitants of Wroclaw, Poland. Ann Agric Environ Med. 2012;19(3):551-6. 28. Stankiewicz-Olczyk J, Bolanowski M, Milewicz A, Jawiarczyk-Przybyłowska A. [The prevalence of metabolic 
syndrome in economically active men]. Endokrynol Otyłość. 2012;8(2):59-64. Polish.

29. Song QB, Zhao Y, Liu YQ, Zhang J, Xin SJ, Dong GH. Sex difference in the prevalence of metabolic syndrome and cardiovascular-related risk factors in urban adults from 33 communities of China: The CHPSNE study. Diab Vasc Dis Res. 2015;12(3):189-98, https://doi. org/10.1177/1479164114562410.

30. Abd Elaziz KM, Gabal MS, Aldafrawy OA, Abou Seif HA, Allam MF. Prevalence of metabolic syndrome and cardiovascular risk factors among voluntary screened middle-aged and elderly Egyptians. J Public Health. 2015;37(4):612-7, https://doi.org/10.1093/pubmed/fdu097.

31. Vishram JKK, Borglykke A, Andreasen AH, Jeppesen J, Ibsen H, Jorgensen T. Impact of age and gender on the prevalence and prognostic importance of the metabolic syndrome and its components in Europeans. The MORGAM Prospective Cohort Project. PLoS One. 2014;9(9):e107294, https:// doi.org/10.1371/journal.pone.0107294.

32. Klein BEK, Klein R, Lee KE. Components of the metabolic syndrome and risk of cardiovascular disease and diabetes in Beaver Dam. Diabetes Care. 2002;25(10):1790-4, https:// doi.org/10.2337/diacare.25.10.1790.

33. Walicka M, Bik W, Sawicka A, Marcinkowska-Suchowierska E. The metabolic syndrome - Does it exist? Postepy Nauk Med. 2013;5B:4-8.

34. Barylski M, Banach M. [Clinical implications of the latest and earlier guidelines for the diagnosis of the metabolic syndrome]. KOF. 2010;2:131-6. Polish.

35. Bielejewska A, Bociek A, Ślusarczyk R, Sadowski M. Cardiac disorders with psychosomatic background. Stud Med 2017;33(4):316-20, https://doi.org/10.5114/ms.2017.72486.

This work is available in Open Access model and licensed under a Creative Commons Attribution-NonCommercial 3.0 Poland License - http://creativecommons.org/ licenses/by-nc/3.0/pl/deed.en. 